\title{
Memória socioeconômica do Ecossistema de Startups de Florianópolis
}

Priscila Machado Borges Sena ${ }^{1}$, Ursula Blattmann ${ }^{2}$, José Antonio Moreiro González ${ }^{3}$, Jéssica Bedin $^{4}$

${ }^{1}$ ORCID: 0000-0002-5612-4315. Programa de Pós-Graduação em Ciência da Informação da Universidade Federal de Santa Catarina, Florianópolis, Santa Catarina.

priscilasena.ufsc@gmail.com.

${ }^{2}$ ORCID: 0000-0002-8834-0987. Programa de Pós-Graduação em Ciência da Informação da Universidade Federal de Santa Catarina, Florianópolis, Santa Catarina. ursula.blattmann@ufsc.br.

${ }^{3}$ ORCID: 0000-0002-8827-158X. Universidad Carlos III de Madrid, Getafe, Madrid. jamore@bib.uc3m.es.

${ }^{4}$ ORCID: 0000-0003-2324-4246. Programa de Pós-Graduação em Ciência da Informação da Universidade Federal de Santa Catarina, Florianópolis, Santa Catarina. Universidade Comunitária da Região de Chapecó - Unochapecó. jessicabedin@unochapeco.edu.br.

Tipo de contribuição: Comunicação Oral

Palavras-chave: Ecossistema de startups; Memória socioeconômica; Organização da informação; Representação da informação; SOC.

\section{Introdução}

Um ambiente propício a interação mútua de distintos atores, com fins de desenvolvimento de startups, foi como o ecossistema de startups foi definido por Sena, Blattmann e Teixeira (2017). Deste modo, é possível inferir que nesses aglomerados circula inúmeros e distintos conhecimentos, advindos das mais diversas formações de seus envolvidos. Por envolver um processo inovador dinâmico a entrada e saída de conhecimento também o é.

Neste contexto, a retenção e preservação do conhecimento tornam-se atividades complexas que poderiam ser facilitadas por meio da organização e representação, com a finalidade de construir a memória socioeconômica do ecossistema de startups de Florianópolis. Uma vez que, geralmente o desenvolvimento socioeconômico é considerado como um importante meio de amenizar as desigualdades de gênero e socioeconômicas no acesso aos serviços de saúde, no uso de serviços e, em última análise, nos resultados (Caldwell, 1986, Evans et al., 1994).

Posto isso, objetiva-se neste trabalho indicar as ações necessárias para a organização e representação do conhecimento no ecossistema de startups de Florianópolis, com vistas a construção de sua memória socioeconômica. Para tal, realiza-se uma pesquisa exploratório descritiva e posterior indicação das ações.

\section{Por que organizar e representar o conhecimento no Ecossistema de Startups?}

Entende-se que a organização do conhecimento é "[...] o processo de modelagem do conhecimento que visa a construção de representações do conhecimento" (Brascher \& Café, 2008, p. 8). E a representação do conhecimento como um modelo de abstração do mundo real, construído para determinada finalidade.

Pode-se considerar que a organização da informação é uma representação da informação, que tem como objeto os documentos, estes podem ser representados por partes ou no todo, de forma 
individual ou em conjunto, abrangendo tanto os aspectos descritivos como os temáticos (Mucalan, 2015).

De acordo, com Brascher e Café (2008) ao realizar o processo de organização do conhecimento, implica também em representar, estabelecer estruturas conceituais que tem como objetivo representar os domínios de conhecimento, bem como a compreensão de fenômenos do mundo.

Já os Sistemas de Organização do Conhecimento (SOCs) ou Knowlwdge organization systems (KOS) podem ser compreendidos como sistemas conceituais, ou tipos de representações do conhecimento, frutos do processo de organização do conhecimento. (Brascher \& Carlan, 2010).

Como exemplos desses sistemas, pode-se citar os tesauros e ontologias que podem ser considerados como linguagens comunicativas, que têm como finalidade representar o conhecimento de um certo domínio, oferecendo controle terminológico, minimizando a ambiguidade e melhorando a comunicação especializada (Soares \& Maculan, 2016).

A polissemia e a ambiguidade são características intrínsecas da linguagem natural, por isso que o uso de SOCs é uma alternativa viável para dar suporte a interpretação adequada das entidades textuais dos documentos e nos termos de busca utilizados pelos usuários (Soares \& Maculan, 2016).

Desta maneira, acredita-se que a organização e representação do conhecimento possam contribuir para os posteriores processos de gestão, e consequentemente para a construção de uma memória que mantenha a dinâmica mais eficaz e eficiente do desenvolvimento do processo inovador existente no ecossistema de startups de Florianópolis. Bem como, disponibilize informações úteis para a sociedade em geral.

\section{Ações necessárias para organização e representação do conhecimento no Ecossistema de Startups de Florianópolis}

Neste trabalho entende-se a memória associada ao desenvolvimento socioeconômico como coletiva. A qual, segundo Halbwachs (2013), trata-se do fato de que a recordação e localização das lembranças não pode ser efetivamente analisado se não for levado em consideração os contextos sociais que atuam como alicerce para o trabalho de reconstrução da memória.

A partir do registro do conhecimento produzido pela organização se torna possível a construção da memória organizacional, definida por Spiller e Pontes (2007, p. 99) como a soma das experiências que uma organização acumula ao longo do tempo, seja nas pessoas, na cultura, nos processos e em seus registros documentados.

Para Menezes (2006, p. 31) a memória organizacional refere-se ao acúmulo de informação, conhecimentos e práticas, reunidos e mantidos por uma organização no decorrer de sua existência, "utilizados para o suporte às suas atividades, seus processos decisórios e para a preservação do seu capital intelectual".

É possível inferir que a memória organizacional é um diferencial competitivo. Para Nascimento et al. (2016), o diferencial competitivo é o resultado do valor que as pessoas que formam a organização atribuem ao conhecimento e a informação. Isso garante que a história da organização seja registrada e usada ao longo do tempo, para fins decisórios, possibilitando que os gestores embasem suas decisões nas ações que foram tomadas no passado.

Assim, as ações consideradas necessárias para a organização e representação do conhecimento no ecossistema de startups de Florianópolis são:

1 Entrevistar por meio de um roteiro semiestruturado os empreendedores de startups, com vistas a obter a origem dos conhecimentos que aplicam em suas empresas e no ecossistema, ou seja, suas fontes de informação. 
2 Relacionar as fontes informação e tipos de informação pertinentes a cada etapa do processo inovador do Ecossistema de Startups de Florianópolis, segmento de tecnologia e inovação.

3 Elaborar modelo de relacionamento das fontes de informação e os tipos de informação com o processo inovador do Ecossistema de Startups de Florianópolis.

Entende-se por fontes de informação, o conceito de Rodrigues e Blattmann (2014, p. 10) que define "como tudo o que gera ou veicula informação". Pode-se dizer que é toda forma que atende as necessidades de informação, incluindo serviços e produtos e informação, pessoas, meio digital, como sites e portais (Rodrigues \& Blattmann, 2014).

No contexto organizacional para fins de gestão, Choo (2006) entende que as fontes de informação podem ser classificas em externas e pessoais, externas e impessoais, internas e pessoais, e internas e impessoais, presentes em ações desenvolvidas por todos os colaborados. É a partir do uso contínuo e efetivo das fontes de informação que se alcança sucesso na pesquisa, no desenvolvimento e na inovação (Cunha, 2016).

Espera-se que por meio das ações descritas se obtenha a organização e representação do conhecimento, consequentemente a categorização dos tipos de informação científica e tecnológica mais utilizadas no Ecossistema de Startups. Bem como, a possibilidade do estabelecimento de folksonomias e taxonomias, que de acordo com Moreiro-Gozález e Bolaños-Mejías (2015) contribuem para a gestão da informação e do conhecimento.

É a taxonomia que possibilita o funcionamento dos sistemas de representação, organização e recuperação de informações em um vocabulário controlado, que em algumas situações isso pode limitar-se a pesquisa do usuário, quando o resultado das buscas é definido com base em uma lista de termos relacionados com o assunto. A taxonomia é construída por pessoas especializadas em organizar informações, e não por profissionais de cada área (Dreyfus, 2001).

Já a folksonomia se diferencia por ser um sistema de classificação criado por usuários individuais, pode-se dizer que é construída pelo povo (Guy \& Tonkin, 2006). A grande diferença está pautada nas variadas formas de representação para um único conceito ou documento, com uma imensidão de significados atribuídos por diferentes indivíduos oriundos de contextos diversos (Lara, 2009).

Deste modo, o uso institucional e empresarial de folksonomias e taxonomias para a representação da informação científica e técnica pode se tornar uma ferramenta útil para a gestão estratégica das atividades, dos procedimentos, dos produtos e dos recursos humanos das empresas, instituições, e entidades de diversas origens (Moreiro-Gozález \& Bolaños-Mejías, 2015).

\section{Considerações Finais}

Enxerga-se que as possibilidades elencadas não são únicas, e a partir de seus desenvolvimentos torna-se possível detalhar suas especificidades e indicar outros desdobramentos. O que reflete na extensão teórico prática da organização do conhecimento, com a busca de lacunas, proposta de soluções pautadas em estudos já realizados, e aplicação por intermédio dos profissionais da informação.

Nesse sentido, acredita-se que o objetivo estabelecido para este trabalho, indicar as ações necessárias para a organização e representação do conhecimento no ecossistema de startups de Florianópolis, com vistas a construção de sua memória socioeconômica foi alcançado. Além disso, conjecturou-se as implicações da organização e representação do conhecimento no ecossistema de startups, refletindo sobre outros desdobramentos, como o estabelecimento de folksonomias e taxonomias. 
Vislumbra-se, o ecossistema de startups de Florianópolis em um campo vasto para estudos pautados nas teorias e práticas da organização do conhecimento, devido aos inúmeros e distintos conhecimentos que nele circulam.

\section{Agradecimentos}

À Coordenação de Aperfeiçoamento de Pessoal de Nível Superior (CAPES) do Brasil por financiar a bolsa de estudos do doutorado em andamento.

\section{Referências}

Brascher, M.; Café, L. (2008). Organização da informação ou organização do conhecimento? In: Anais do Encontro Nacional de Pesquisa em Ciência da Informação, 9.

Brasher, M. \& Carlan, E. (2010). Sistemas de organização do conhecimento: antigas e novas linguagens. In: Robredo, J.; Brascher, M. (Org.). Passeios pelo bosque da informação: estudos sobre a representação e organização da informação e do conhecimento. Brasília DF: IBICT.

Caldwell, J. C. (1986). Routes to low mortality in poor countries. Pop. Dev. Rev., 12(2), 171-220.

Choo, C. W. (2003). A organização do conhecimento: como as organizações usam a informação para criar significado, construir conhecimento e tomar decisões. São Paulo: Senac São Paulo.

Cunha, M. B. D. (2001). Para saber mais: fontes de informação em ciência e tecnologia. Brasília: Brinquet de Lemos.

Dreyfus, H. L. (2001). On the internet. Routledge.

Guy, M., \& Tonkin, E. (2006). Folksonomies: Tidying up tags?. D-lib Magazine, 12(1).

Halbwachs, M. (2013). A memória coletiva (2a ed.). Tradução de Beatriz Sidou. São Paulo: Centauro.

Lara, M. L. (2009). Linguística documentária: seleção de conceitos. 2009. 178 f (Doctoral dissertation, Tese (Livre-docência)-Escola de Comunicações e Artes, Universidade de São Paulo, São Paulo).

Menezes, E. M. (2006). Estruturação da memória organizacional de uma instituição em iminência de evasão de especialistas: um estudo de caso da CONAB. Mestrado. Universidade Católica de Brasília.

Moreiro-González, J. A., \& Bolaños-Mejías, C. (2015). Papel de los vocabularios semánticos en la economía en red. Uso institucional y empresarial de folksonomías y taxonomías. PRISMA. COM, (29), 121-138. Recuperado em 5 janeiro, 2019, de http://pentaho.letras.up.pt/ojs/index.php/prismacom/article/view/1834

Maculan, B. C. M. S. (2015). Estudo e aplicação de metodologia para reengenharia de tesauro: remodelagem do THESAGRO. 
Nascimento, N. M., de Souza, J. S. F., Valentim, M. L. P., \& Moro-Cabero, M. M. (2016). Gerenciamento dos fluxos de informação como requisito para a preservação da memória organizacional: um diferencial competitivo. Perspectivas em Gestão \& Conhecimento, 6(1), 29-44.

Rodrigues, C., \& Blattmann, U. (2014). Gestão da informação e a importância do uso de fontes de informação para geração de conhecimento. Perspectivas em Ciência da Informação, 19(3), 04-29.

Sena, P., Blattmann, U., \& Teixeira, C. (2017). Ecossistema de Startups em Florianópolis: possibilidades para profissionais da Biblioteconomia. RBBD. Revista Brasileira de Biblioteconomia e Documentação, 13, 2571-2588. Recuperado em 5 janeiro, 2019, de https://rbbd.febab.org.br/rbbd/article/view/864/957

Soares, F. M. \& Maculan, B. C. M. S. (2016). Organização e representação do conhecimento em tesauros: uso do sistema e-termos. Seminário em Ciência da Informação: fenômenos emergentes na Ciência da Informação.

Spiller, A., \& Cunha Pontes, C. C. (2007). Memória organizacional e reutilização do conhecimento técnico em uma empresa do setor eletroeletrônico no Brasil. Revista Brasileira de Gestão de Negócios, 9(25). 